DOI: $10.31249 / \mathrm{rsm} / 2018.04 .18$

\title{
О.А. Хлопов
}

\section{КОНЦЕПЦИЯ САЕРЖИВАНИЯ \\ И ПРОБАЕМЫ ЯАЕРНОЙ БЕЗОПАСНОСТИ В РОССИЙСКО-АМЕРИКАНСКИХ ОТНОШЕНИЯХ}

Аннотация. В статье описывается эволюция и современное состояние концепций ядерного сдержсиания в США и СССР в ХХ в., а также современное состояние этих концепций. Делается вывод о том, что ядерное сдерживание не потеряло своей актуальности и в XXI в., а современной России и США необходимо возобновить диалог по проблемам сокращения ядерных вооружений.

Ключевые слова: ядерное сдерживание, международная безопасность, разоружение, военная доктрина, ядерное оружие, национальные интересы, российскоамериканские отношения, Россия, США.

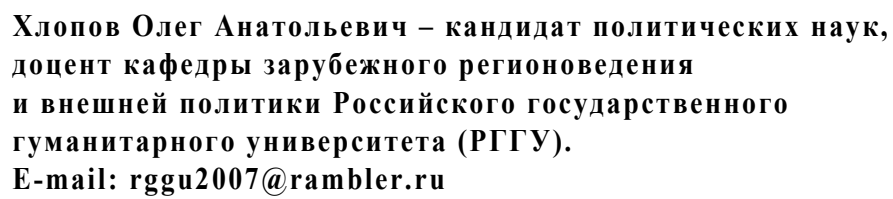

O.A. Khlopov. Concept of Nuclear Deterrence and Nuclear Security in Russia-American Relations

Abstract. The article deals with the evolution and current state of nuclear deterrence concepts in the USA and the USSR in the XX century and the current state of these concepts. The author concludes that nuclear deterrence has not lost its relevance in the XXI st century, and modern Russia and the United States should resume the dialogue on nuclear arms reduction.

Keywords: nuclear deterrence, international security, disarmament, nuclear weapons, military strategy, national interests, Russian-American relations, Russia, USA.

Khlopov Oleg Anatolyevich - Candidate of Political Sciences,

Associate Professor, Russian State University

for the Humanities (RGGU). E-mail: rggu2007@rambler.ru 


\section{ЯАерное оружие как инструмент сдерживания. Теория и практика}

В процессе формирования новой «постбиполярной» мировой системы, когда обостряются противоречия между США и Россией, возрастает интерес к механизмам, которые могут стать основой новой глобальной системы безопасности XXI в. Одним из таких механизмов является ядерное сдержсивание. Этим термином обозначают военную доктрину, согласно которой врага следует удерживать от применения ядерного оружия под угрозой нанесения ответного удара.

В условиях идеологического противостояния СССР и США эта доктрина постоянно изменялась. Одной из первых была сформулирована концепция первого удара, согласно которой одна из сторон нейтрализует ядерный потенциал другой стороны, лишает ее возможности нанести ответный удар. Термин массированное возмездие (massive retaliation) был впервые упомянут американским госсекретарем Дж. Даллесом в январе 1954 г. [12]. Суть этой стратегии сводится к тому, что если против США, их союзников будет совершено нападение с применением обычного оружия, США могут ответить ядерным ударом. Содержание следующего этапа эволюции ядерного оружия неразрывно связано с концепцией взаимного гарантированного уничтожения (mutually assured destruction) [14]. Согласно этой концепции, в условиях обладания сторонами большого количества ядерных боезарядов их применение приведет к полному уничтожению обеих сторон.

Идеи ограниченного применения ядерного оружия и ограниченного ядерного конфликта появились в конце 1950-х годов. Американские военные эксперты разрабатывали три сценария использования ядерного оружия. Согласно первому сценарию, необходимо нанести устрашающий, демонстративный ядерный удар, когда противник ставится перед выбором: война или мир. Задача второго сценария - нанести удар по военным объектам противника, чтобы лишить его возможности произвести ответный удар. Третий сценарий предполагает направить ядерный удар на ликвидацию политического и военного руководства противника. Администрации президентов США Р. Никсона и Дж. Форда, подвергая сомнению концепцию взаимного гарантированного уничтожения, разработали документ «NSDM-242», согласно которому появлялась возможность применять «ограниченные ядерные удары» - наносить ядерные удары исключительно по военным целям [9].

Установившийся к 1970-м годам стратегический паритет (в обеих странах приняты на вооружение межконтинентальные баллистические ракеты наземного и морского базирования) позволил двум странам пойти на достижение военно-политических договоренностей. Именно возможность взаимного уничтожения стала основой советско-американского сотрудничества 
в области ядерной безопасности и заложили основы политики разрядки в 1970-е годы.

В 1972 г. между СССР и США были подписаны первый «Договор об ограничении стратегических вооружений» (OCB-1) и «Договор по ограничению систем противоракетной обороны» (ПРО), которые ограничивали количество баллистических ракет и пусковых установок СССР и США уровнем начала 1972 г. Сторонам не разрешалось иметь развернутые системы ПРО космического, воздушного и морского базирования. Таким образом, США и СССР лишались возможности сбивать баллистические ракеты друг друга и их территории становились уязвимыми для ядерных ударов. Однако дополнительный протокол, подписанный в 1974 г., разрешал сторонам иметь по одной системе ПРО на своей территории.

Следующий президент США Дж. Картер и советник по вопросам национальной безопасности Зб. Бжезинский тем не менее продолжили рассматривать возможности гибкого применения ядерного оружия. Была разработана стратегия «компенсаиии» (countervailing), направленная на то, чтобы сделать войну психологически немыслимой для Советского Союза. Новая технология наблюдения позволяла применять тактику «взгляд - удар - взгляд», когда США определяли бы цели, проводили ядерный удар и затем проверяли, было ли нападение успешно. Многие эксперты считали «Директиву PD59» излишне опасной [8], и в 1979 г. США пошли на подписание Договора ОСВ-2, согласно которому к 1981 г. стороны обязывались сократить количество стратегических носителей до 2150 единиц.

Администрация следующего президента, Р. Рейгана, внесла несколько главных изменений в ядерную стратегию Дж. Картера. Согласно документу «NSDD-13», США могли выиграть ядерную войну, а не только гарантировать потери советской стороны. С этой целью было заявлено о создании Cттратегической оборонной инициативы (СОИ), системы противоракетной обороны, разработанной для перехвата летящих боеголовок [7]. В период правления президента Рейгана произошла существенная модернизация вооруженных сил и ядерного оружия, с одновременным подписанием с Советским Союзом соглашений о контроле над стратегическими вооружениями.

Перестройка и новое мышление в СССР, провозглашенные М. Горбачёвым, позволили США и СССР пойти на дальнейшее сокращение арсеналов ядерного оружия. В декабре 1987 г. в Вашингтоне М.С. Горбачёв и Р. Рейган подписали бессрочный «Договор о ликвидации ракет средней и малой дальности» (РСМД). Согласно договору, обе стороны обязались не производить, не испытывать и не развертывать крылатые и баллистические ракеты наземного базирования средней (от 1 тыс. до 5500 км) и малой (от 500 до 1 тыс. км) дальности. В 1991 г. между Горбачёвым и Дж. Бушем был подписан «Договор о сокращении стратегических наступательных вооружений» (CHB-1). 
Согласно договору, каждая сторона обязывалась до 1999 г. сократить свои ядерные заряды до 6 тыс. единиц [7].

Из-за распада СССР, когда ядерное оружие оказалось на территории других государств: Беларуси, Казахстана и Украины, реализация договора стала затруднительной. В связи с этим в 1992 г. в Лиссабоне США, Россией, Украиной, Казахстаном и Беларусью был подписан дополнительный протокол к CHB-1 - Лиссабонский договор, по которому Украина, Казахстан и Беларусь были признаны сторонами договора СНB-1, а все ядерное оружие, находящееся на территории этих четырех государств, после роспуска СССР подлежало уничтожению или передаче под контроль России. Эти государства согласились присоединиться к Договору о нераспространении ядерного оружия.

Новое российское руководство продолжило курс на сокращение запасов ядерного оружия. В 1993 г. между Б. Ельциным и Дж. Бушем был подписан «Договор о сокращении стратегических наступательных вооружений» (CHB-2), который предусматривал, что каждая сторона сократит количество своих ядерных боеголовок до 3500 к 2003 г. Несмотря на все сложности, которые стали появляться в российско-американских отношениях, российская Госдума все же ратифицировала договор в 2000 г.

Но в 2002 г. США в одностороннем порядке вышли из договора по ПРО. В ответ на это российское руководство приняло решение выйти из договора CHB-2. На его основании был подписан новый «Договор о сокращении стратегических наступательных потенциалов» (СНП). С прекращением действия договора по ПРО утратил динамику процесс создания региональных зон, свободных от ядерного оружия, обострились военно-политические противоречия между США и Россией, но продолжался поиск компромиссов по дальнейшему сокращению количества ядерных боезарядов. В 2009 г. президент Б. Обама в Праге произнес речь, призывая покончить с ядерным оружием. Б. Обама заявил, что для преодоления угроз ядерного терроризма и распространения ядерного оружия США будут «искать мир и безопасность без ядерного оружия» [13].

8 апреля 2010 г. Россия и США подписали в Праге новый «Договор о сокращении наступательных вооружений» (CHB-3), который вступил в силу 5 февраля 2011 г. Это соглашение сроком на десять лет обязывает стороны сократить число развернутых ядерных боезарядов на межконтинентальных баллистических ракетах до 1550 единиц, ракеты морского и наземного базирования и стратегические бомбардировщики до 700 единиц [16].

В целом, несмотря на все сложности и трудности, Россия и США получили большой опыт как в области ограничения наступательного ядерного оружия, так и в области нераспространения оружия массового поражения. Этот опыт и стал фундаментом глобальной ядерной стабильности. 


\section{Программа Нанна-Аугара как позитивное решение проблемы ядерной безопасности}

В 1991 г. США выступили с инициативой оказать Москве содействие в сохранении контроля над ядерным потенциалом. Начать программу относительно безопасных и надежных перевозок, хранения и уничтожения оружия предложили сенаторы Сэмьюэл Нанн и Ричард Лугар. Год спустя было подписано «Соглашение между РФ и США относительно безопасных и надежных перевозок, хранения и уничтожения оружия и предотвращения распространения оружия» [1, с. 119].

Законы «Об уменьшении советской военной угрозы» от 12 декабря 1991 г. и «О совместном уменьшении угрозы» от 11 октября 1993 г. предусматривали выделение из бюджета США значительных средств для сокращения ядерного арсенала СССР / России. В целом до 1999 г. было выделено 1,7 млрд долл., в том числе России - 1,22 млрд долл., Украине - 521 млн долл., Казахстану 172,8 млн долл., Беларуси - 83,5 млн долл., Грузии - 1,3 млн долл. [17]. Соглашения охватывали два важных аспекта - безопасность хранения ядерного оружия и безопасность его утилизации и вывоза с территории Украины, Казахстана, Грузии [5].

В июне 2013 г. соглашение по программе Нанна-Лугара было продлено с изменениями. Американские эксперты лишались полного доступа на ядерные объекты РФ, было сокращено количество российско-американских проектов в атомной отрасли. После кризиса на Украине в 2014 г. США прекратили сотрудничество по физической защите российских атомных производств.

Программу Нанна-Лугара, несмотря на ряд ее недостатков, следует считать наиболее успешным примером сотрудничества России и США в области ядерной безопасности. Программа соответствовала содержанию ядерной политики как США, так и России, отвечала целям минимизировать ядерную угрозу, сократить количество ядерных боезарядов, сузить географию их размещения.

\section{Современные подходы \\ к яАерной политике США и России}

Сегодня в американских экспертных, аналитических и академических кругах по-прежнему ведется дискуссия о роли ядерного сдерживания в международных отношениях.

После распада Советского Союза ядерная стратегия для США стала одной из ключевых проблем национальной безопасности. Главный стратегический противник, который инициировал окончание холодной войны, в одностороннем порядке отказался от своего геополитического присутствия в Восточной Европе и других регионах мира, и, как показалось многим, пере- 
стал существовать. У американских военных стратегов сразу же возникли вопросы относительно того, кого считать своим противником и против кого использовать ядерное оружие. На эти и другие вопросы США попытались ответить в новом документе под названием «Обзор ядерной политики» (Nuclear Posture Review), который уже выдержал несколько изданий - 1993, 2002,2010 и 2018 гг.

Последний из этих «Обзоров», опубликованный Пентагоном в феврале 2018 г., анализирует уровень ядерной безопасности в мире; значительное внимание в нем уделяется России и Китаю. Отмечается, что Соединенные Штаты не хотят считать ни Россию, ни Китай своими противниками и стараются поддерживать стабильные отношения с обеими странами. В документе подчеркивается, что ядерные силы и средства США не могут предотвратить конфликт во всех без исключения случаях, но они способствуют сдерживанию агрессии как с применением, так и без применения ядерного оружия. По сути, в «Обзоре» 2018 г. сформулирована новая ядерная концепция оптимизированного и расширенного сдерживания, согласно которой Соединенные Штаты будут применять гибкий подход к эффективному сдерживанию, в зависимости от вида противника, характера угроз и конкретной ситуации. В документе подчеркивается, что США «взяли на себя официальные обязательства по расширенному сдерживанию», которое гарантируют безопасность союзников в Европе, Тихоокеанском регионе и Азии.

В официальных документах стратегического характера («Национальной военной стратегии» и «Стратегии национальной безопасности» 2015 г., «Стратегии национальной обороны» 2018 г. и др.) отражаются изменения ядерной политики США на современном этапе [10; 11]. Из этих документов следует, что, во-первых, ядерное сдерживание все же остается необходимым в отношении Китая и России. Во-вторых, ядерное оружие не является для США единственным инструментом реагирования на новые угрозы и вызовы. В-третьих, стремление США к сокращению ядерного арсенала вызвано ставкой на развитие инновационных технологий, которые позволяют создавать и совершенствовать новые типы оружия.

В Военной доктрине Российской Федерации, утвержденной В.В. Путиным в 2000 г., на основании анализа военных угроз (первый этап расширения НАТО, использование США и их союзниками в одностороннем порядке военной силы в Югославии) излагались четкие позиции России в отношении ядерного оружия. Россия оставляла за собой право использования ядерного оружия в ответ на угрозу применения против нее и (или) ее союзников химического, бактериологического и ядерного оружия, а также в ответ на агрессию с применением обычного оружия в ситуациях, которые она будет считать критическими для безопасности государства [3]. Последняя редакция Военной доктрины Российской Федерации была принята в 2014 г. В ней 
утверждается, что в основе военной политики Российской Федерации лежит идея недопущения ядерного военного конфликта [4].

Таким образом, концепция ядерного сдерживания не потеряла свою значимость и в XXI в., что подтверждается выводами ведущих российских экспертов в области ядерной безопасности и политики [см., напр.: $1 ; 2 ; 5 ; 6]$. Важной мыслью, которую разделяет экспертное сообщество как в России, так и в США, является мысль о необходимости возобновления международноправовой практики заключения соглашений по сокращению (без полного уничтожения) стратегических ядерных вооружений.

\section{Библиография}

1. Александрия О.М. Ядерная безопасность и российско-американское взаимодействие // Международные процессы. 2014. Т. 12. № 4. С. 116-127.

2. Арбатов А.Г. До основания, а затем... // Россия в глобальной политике [Электронный pecypc]. 2017. № 3. URL: http://globalaffairs.ru/number/Do-osnovaniya-a-zatem-18807 (Дата обращения: 02.02.2018.)

3. Военная доктрина Российской Федерации [2000 г.] // Президент России: Официальный сайт [Электронный ресурc]. URL: http://www.kremlin.ru/acts/bank/15386 (Дата обращения: 14.02.2018.)

4. Военная доктрина Российской Федерации [2014 г.] // Российская газета [Электронный pecypc]. 2014. 30 дек. URL:https://rg.ru/2014/12/30/doktrina-dok.html (Дата обращения: 14.02.2018.)

5. Дворкин В.3. Краткие комментарии к прекращению программы Нанна-Лугара // Московский центр Карнеги [Электронный ресурс]. 2015. 6 февр. URL: http://carnegie.ru/2015/02/06/ ru-pub-58994 (Дата обращения: 04.02.2018.)

6. Караганов С.А. О новом ядерном мире // Россия в глобальной политике [Электронный pecypc]. 2017.№ 2. 4 апр. URL: http://www.globalaffairs.ru/number/O-novom-yadernom-mire18644 (Дата обращения: 29.01.2018.)

7. Daryl G. Kimball, Looking Back: The Nuclear Arms Control Legacy of Ronald Reagan // Arms Control Association: Official Website [Электронный ресурс]. 2004. 1 July. URL: https:// www.armscontrol.org/act/2004_07-08/Reagan (Дата обращения: 14.03.2018.)

8. Jimmy Carter's Controversial Nuclear Targeting Directive PD-59 Declassified// The National Security Archive [Электронный ресурc]. 2012. Sept. 14. URL: http://nsarchive.gwu.edu/ nukevault/ebb390/ (Дата обращения: 28.02.2018.)

9. Kunsman D.M., Lawson D.B. A Primer on U.S. Nuclear Strategic Policy: Sandia Report 2001-0053 // Sandia National Laboratory [Электронный ресурс]. 2001. Jan. URL: http://prod. sandia.gov/techlib/access-control.cgi/2001/010053.pdf (Дата обращения: 05.03.2018.)

10. National Military Strategy of the Unites State of America: Unites State Millitary's Contribution to National Security. June 2015 // National Security Strategy Archive [Электронный ресурс]. URL: http://nssarchive.us/NMS/2015.pdf (Дата обращения: 07.02.2018.)

11. National Security Strategy. 2015. February // National Security Strategy Archive [Электронный ресурс]. URL: http://nssarchive.us/wp-content/uploads/2015/02/2015.pdf (Дата обращения: 07.03.2018.)

12. Nuclear Weapons Employment Strategy of the United States. 2013. June 19 // The White House. President Barack Obama [Электронный pecypc]. URL: https://obamawhitehouse.archives. 
gov/the-press-office/2013/06/19/fact-sheet-nuclear-weapons-employment-strategy-united-states (Дата обращения: 15.01.2018.)

13. Remarks by President Barack Obama In Prague. 2009. April 5 // The White House. President Barack Obama [Электронный ресурc]. URL: https://obamawhitehouse.archives.gov/the-pressoffice/remarks-president-barack-obama-prague-delivered (Дата обращения: 08.02.2018.)

14. Schelling Th. The Strategy of Conflict, Harvard University Press, Cambridge, 1960. In paperback: Oxford University Press, New York, 1963. Harvard University Press paperback, 1980. $309 \mathrm{p}$.

15. The Strategy of Massive Retaliation. Speech of Secretary of State John Foster Dulles before the Council on Foreign Relations. 1954. 12 January // Free Public [Электронный pecypc]. URL: http://www.freerepublic.com/focus/f-news/1556858/posts (Дата обращения: 02.02.2018.)

16. Treaty Between The United States of America And The Russian Federation On Measures For The Further Reduction And Limitations of Strategic Offensive Arms // U.S. Department of State: Official Website [Электронный pecypc]. URL: https:/www.state.gov/documents/organization/ 140035.pdf (Дата обращения: 25.03.2018.)

17. Woolf A.F. Nonproliferation and Threat Reduction Assistance: U.S. Programs in the Former Soviet Union. CRS Report for Congress // Federation of American Scientists. 2012. March 6. URL: http://www.fas.org/sgp/crs/nuke/RL31957.pdf (Дата обращения: 15.03.2018.)

\section{References}

Aleksandrija O.M. Jadernaja bezopasnost' i rossijsko-amerikanskoe vzaimodejstvii // Mezhdunarodnye processy. 2014. Vol. 12. N 4. P. 116-127.

Arbatov A.G. Do osnovanija, a zatem... // Rossija v global'noj politike [Jelektronnyj resurs]. 2017. N 3. URL: http://globalaffairs.ru/number/Do-osnovaniya-a-zatem-18807 (Data obrashhenija: 02.02.2018.)

Daryl G. Kimball, Looking Back: The Nuclear Arms Control Legacy of Ronald Reagan // Arms Control Association: Official Website [Jelektronnyj resurs]. 2004. 1 July. URL: https://www. armscontrol.org/act/2004_07-08/Reagan (Data obrashhenija: 14.03.2018.)

Dvorkin V.Z. Kratkie kommentarii k prekrashheniju programmy Nanna-Lugara // Moskovskij centr Karnegi [Jelektronnyj resurs]. 2015. Feb. 6. URL: http://carnegie.ru/2015/02/06/ru-pub-58994 (Data obrashhenija: 04.02.2018.)

Jimmy Carter's Controversial Nuclear Targeting Directive PD-59 Declassified // The National Security Archive [Jelektronnyj resurs]. 2012. Sept. 14. URL: http://nsarchive.gwu.edu/nukevault/ ebb390/ (Data obrashhenija: 28.02.2018.)

Karaganov S.A. O novom jadernom mire // Rossija v global'noj politike [Jelektronnyj resurs]. 2017. N 2. 4 apr. URL: http://www.globalaffairs.ru/number/O-novom-yadernom-mire-18644 (Data obrashhenija: 29.01.2018.)

Kunsman D.M., Lawson D.V. A Primer on U.S. Nuclear Strategic Policy: Sandia Report 2001-0053 // Sandia National Laboratory [Jelektronnyj resurs]. 2001. Jan. URL: http://prod.sandia. gov/techlib/access-control.cgi/2001/010053.pdf (Data obrashhenija: 05.03.2018.)

National Military Strategy of the Unites State of America: Unites State Millitary's Contribution to National Security. June 2015 // National Security Strategy Archive [Jelektronnyj resurs]. URL: http://nssarchive.us/NMS/2015.pdf (Data obrashhenija: 07.02.2018.)

National Security Strategy. 2015. February // National Security Strategy Archive [Jelektronnyj resurs]. URL: http://nssarchive.us/wp-content/uploads/2015/02/2015.pdf (Data obrashhenija: 07.03.2018.)

Nuclear Weapons Employment Strategy of the United States. 2013. June 19 // The White House. President Barack Obama [Jelektronnyj resurs]. URL: https:/obamawhitehouse.archives.gov/ 


\section{РАЗМЫШЛЕНИЯ, СООБЩЕНИЯ, КОММЕНТАРИИ}

the-press-office/2013/06/19/fact-sheet-nuclear-weapons-employment-strategy-united-states

(Data obrashhenija: 15.01.2018.)

Remarks By President Barack Obama In Prague. 2009. April 5 // The White House. President Barack Obama [Jelektronnyj resurs]. URL: https://obamawhitehouse.archives.gov/the-pressoffice/remarks-president-barack-obama-prague-delivered (Data obrashhenija: 08.02.2018.)

Schelling Th. The Strategy of Conflict, Harvard University Press, Cambridge, 1960. In paperback: Oxford University Press, New York, 1963. Harvard University Press paperback, 1980. 309 p.

The Strategy of Massive Retaliation. Speech of Secretary of State John Foster Dulles before the Council on Foreign Relations. 1954. 12 January // Free Public [Jelektronnyj resurs]. URL: http://www.freerepublic.com/focus/f-news/1556858/posts (Data obrashhenija: 02.02.2018).

Treaty Between The United States of America And The Russian Federation On Measures For The Further Reduction And Limitations of Strategic Offensive Arms // U.S. Department of State: Official Website [Jelektronnyj resurs]. URL: https:/www.state.gov/documents/organization/ 140035.pdf (Data obrashhenija: 25.03.2018.)

Voennaja doktrina Rossijskoj Federacii [2000 g.] // Prezident Rossii: Official Website [Jelektronnyj resurs]. URL: http://www.kremlin.ru/acts/bank/15386 (Data obrashhenija: 14.02.2018.)

Voennaja doktrina Rossijskoj Federacii [2014 g.] // Rossijskaja gazeta [Jelektronnyj resurs]. 2014. 30 dek. URL: https://rg.ru/2014/12/30/doktrina-dok.html (Data obrashhenija: 14.02.2018.)

Woolf A.F. Nonproliferation and Threat Reduction Assistance: U.S. Programs in the Former Soviet Union. CRS Report for Congress // Federation of American Scientists. 2012. March 6. URL: http://www.fas.org/sgp/crs/nuke/RL31957.pdf (Data obrashhenija: 15.03.2018.) 